\title{
Tecendo e retecendo a mortalha de corpos ausentes
}

\author{
Angí́cia Gomes Pereira Mourão \\ RESENHA: MUKASONGA, Scholastique. A \\ mulher de pés descalços. São Paulo: Nós, \\ 2017. Tradução: Marília Garcia.
}

Em 2017, os leitores e o mercado editorial brasileiro conheciam a ruandesa, radicada na França, Scholastique Mukasonga. Naquele ano, ela tinha dois de seus títulos ${ }^{1}$ lançados pela editora Nós e era uma das convidadas principais da Festa Literária Internacional de Paraty, um dos maiores eventos literários que acontece anualmente, no estado do Rio de Janeiro. A presença de Mukasonga e sua escrita foram (e ainda são) pauta de inúmeras matérias de jornais, cadernos especializados e blogs de aficionados por literatura (CAZES, 2017; CONSTANT, 2017; DOMINGOS, 2017; GABRIEL, 2017; MELLO, 2017; NETO, 2017; NEVES, 2017; SANTOS, 2017; TORRES; CAZES, 2017; KUBOTA, 2018; RODRIGUES, 2018).

Dessa forma, ficamos sabendo que essa autora da diáspora africana havia nascido em 1956, em Ruanda, e havia testemunhado

\begin{abstract}
1 Em 2017, os dois livros de Mukasonga lançados pela editora Nós no Brasil foram Nossa Senhora do Nilo e A mulher de pés descalços. Em 2018, a mesma editora publicou Baratas, outro de seus títulos autobiográficos, sobre a violência vivida pelos tutsis em Ruanda (cf. RODRIGUES, 2018). Ressalto que essa cronologia de lançamentos da autora em nosso país não corresponde à de suas obras publicadas pela editora francesa Gallimard. Sendo assim, antes de chegar ao Brasil, essa autora africana de expressão francesa publicou Inyenzi ou les cafards (2006), La femme aux pieds nus (2008), L'Iguifou (2010) e Notre-Dame du Nil (2012).
\end{abstract}

\section{Angícia Gomes Pereira Mourão}

Doutoranda no Programa de Pós-Graduação em Antropologia Social da Universidade Federal do Rio Grande do Sul (PPGAS - UFRGS). Mestre em Sociologia e graduada em Ciências Sociais pela UECE. Especialista em Estudos Clássicos e licenciada em Letras Português-Espanhol pela UFC. E-mail: angicia@ gmail.com. 
boa parte da disputa "inventada" (GABRIEL, 2017) entre as etnias hutu e tutsi, sendo esta a de Mukasonga. Como pertencente à minoria étnica de Ruanda, ela viveu, durante a infância e parte da juventude, em um campo de refugiados, onde conheceu a assimilação religiosa pela Igreja católica, obrigatória para aqueles que quisessem ter ou que desejassem que seus filhos tivessem acesso à educação e a empregos mais rentáveis. A autora também se deparou com a perseguição política prolongada, a vista grossa da comunidade internacional e o genocídio perpetrado pelos hutus, em 1994, quando cerca de 800 mil ruandeses foram mortos a machadadas e a golpes de facão, durante 100 dias de uma tragédia nem sempre anunciada pela mídia internacional. É bem verdade que Mukasonga não vivia em Ruanda desde 1992, mas nem por isso ela deixou de ter seu corpo marcado pela violência, uma vez que 37 membros de sua família foram mortos nesta ocasião (CONSTANT, 2017; GABRIEL, 2017; NEVES, 2017;RODRIGUES, 2018) e ela apenas teve a confirmação de seus nomes escritos em uma folha de caderno escolar enviada como correspondência (NEVES, 2017; RODRIGUES, 2018).

Essa trajetória de dores e de resistência marca todas as narrativas de Mukasonga que, por ora, encontramos disponíveis nas livrarias brasileiras. Particularmente em A mulher de pés descalços, a autora dedica suas memórias à mãe, uma das tantas mulheres tutsis que trabalhavam arduamente em plantações, assim como no cuidado dos filhos e da casa, sempre de pés descalços. Já no prefácio do livro, Mukasonga adverte para uma vivência e uma narrativa de perdas e cisões, quando diz que ela e duas irmãs tinham um nome de batismo, escolhido pelo pai, e outro nome, "o nome de verdade" ${ }^{2}$, pelo qual a mãe as chamava.

2 O uso de aspas e a falta de indicação da página dessa citação (e das demais similares a ela) são intencionais. Estou propondo fazer citações diretas apenas das palavras de Mukasonga usadas em A mulher de pés descalços, pois apoio a proposta da autora de lembrar e registrar vidas e culturas dizimadas pelos genocídios desencarrilhados pela colonização europeia na África e que costumam ficar à margem de ou ser invisibilizadas por narrativas hegemônicas. Não posso, portanto, delas me apropriar. Cabe a mim apenas ouvi-las atentamente de meu lugar. A falta de indicação das páginas do livro de onde retirei os trechos citados se deve tanto ao respeito que tento prestar ao registro 
Sua mãe, Stefania, é a personagem principal dessa história, sendo apresentada, desde o princípio, como uma mulher ocupada nas inúmeras tarefas do cotidiano e especialmente alerta para garantir a sobrevivência dos filhos e dos costumes mais antigos de sua etnia. Curandeira e "casamenteira de mão cheia", Stefania chamava as filhas para lembrá-las de cobrirem o seu corpo morto, pois "ninguém pode ver o cadáver de uma mãe". A impressão que nos fica de imediato e que a autora confirma em inúmeras entrevistas é que sua história é a mortalha de palavras que ela oferece à mãe, como pagamento pela mortalha de tecido que deveria ter coberto seu cadáver, mas que suas filhas não puderam oferecer-lhe, quando foi assassinada em 1994.

O livro é composto por 10 capítulos, prefácio e posfácio. Cada capítulo trata de um tema diferente da vida de inúmeros "exilados do interior" de Ruanda, deportados para a pequena cidade de Nyamata, a sudeste do país, onde o sono, a fome e o ambiente hostil deveriam se encarregar de matar os sobreviventes tutsis daquela guerra entre etnias irmãs. A princípio, esses desterrados esperavam voltar para casa, mas eventualmente compreendiam que "nunca veriam outra vez as colinas de onde foram arrancados" e "com coragem e solidariedade" sobreviviam às adversidades. A narrativa de Mukasonga tem início no ano de 1963, ano seguinte à declaração de independência de Ruanda do estatuto de protetorado belga, cuja autoridade sanguinolenta imperava desde o fim da Segunda Guerra Mundial. Já seu desenrolar e desfecho passam por outros momentos e mesmo pelo genocídio de 1994, de forma mais ou menos demarcada pela autora. A narrativa, portanto, passa-se no período de nascimento e formação de um Estado-nação sob o ponto de vista dos refugiados, uma construção sem ídolos nem glória, repleta de violência física e simbólica assim como de reconhecidas relações de dominação.

oral de onde essas palavras se originaram como também ao modo como elas me soaram, no que há de subjetivo na prática de leitura. No entanto, precisei citar outras vozes (outra bibliografia) e, para garantir a clareza de entendimento do meu potencial leitor, cito essas outras falas de forma indireta, costumeiramente de acordo com as normas de publicação vigentes. 
Diante das constantes cenas de violência praticadas pelos militares e jovens hutus extremistas em Bugesera, a mãe de Mukasonga só tinha um propósito: salvar os filhos. Esse é o nome dado ao primeiro capítulo do relato, dedicado a narrar as inúmeras estratégias de sobrevivência elaboradas por Stefania. Não ser surpreendida, informar-se sobre a rotina dos vizinhos, aumentar a vigília durante a noite e saber ler os sinais da natureza eram os ensinamentos maternos mais importantes. A maternidade vivida por uma "exilada do interior" não era a mesma de uma ruandesa qualquer. Por isso, "mamãe espreitava os barulhos sem parar" com "um sexto sentido, o da presa que está sempre alerta". Era preciso "fugir e se esconder no matagal espesso", quando havia tempo. No caminho da fuga, sacos de provisões eram escondidos e esconderijos dentro de casa também eram ardilosamente preparados, pois "mamãe não deixava nada nas mãos do acaso". A melhor estratégia de fuga e sobrevivência era atravessar a fronteira de Nyamata com o Burundi, para onde Mukasonga foi aos18 anos.Talvez por causa do cerco cada vez mais apertado dos militares, essa estratégia servia apenas para garantir a sobrevivência dos filhos de Stefania, mas não a dela nem a do marido, que não pensavam em se exilar. Mukasonga deixa claro que não se escolhe o exílio em vida e, para alguns, como sua mãe, não se escolhe o exílio nem diante da morte. "Eles seriam mortos na sua terra; ali, eles se deixariam assassinar".

O terceiro e o quarto capítulos do livro expressam a resistência tutsi em dois diferentes aspectos: o da construção do lar e o do cultivo do sorgo, um gênero alimentar particular de Ruanda, conhecido no Brasil como milho-zaburro.

A casa de pau a pique de Stefania, construída no campo de refugiados pelo seu marido e pelo seu filho mais velho, não protegia a família, pois era "vazia de Espíritos". De acordo com os costumes tutsis, as paredes retilíneas dessa casa e os ângulos formados por seus encontros não permitiam que ela encontrasse um canto para se sentar e a porta retangular expunha sua família a olhares indiscretos, malefícios e ameaças. "O cúmulo da obscenidade", que era comer tendo estranhos olhando para si, fazia reverberar reclamações na boca de Stefania. Para ela, era preciso construir um inzu, 
casa de palha trançada de acordo com os costumes tradicionais de Ruanda, onde se aprendia a guiar pelo coração em meio à penumbra e onde Stefania "poderia levar uma verdadeira vida de mulher, uma verdadeira vida de mãe de família". Essas casas, que atualmente "só podem ser vistas nos museus", pareceram restaurar a dignidade de Stefania, que lhes atribuía poderes inclusive sobre os militares, os quais evitavam saqueá-las.

No capítulo sobre o sorgo, Mukasonga descreve o trabalho constante das mulheres tutsis na agricultura e pecuária local. O sorgo "ocupava um lugar à parte" nessa cultura, pois "tinha uma dignidade" em Ruanda. "Era um talismã contra a fome", ao ser fonte dos mais diversos alimentos, como os inopfus desejados pelas crianças, a cerveja que "era a própria razão de convívio entre os ruandeses" e a agacoma para fortificar os corpos doentes ou idosos. Mukansonga desenha os detalhes nos modos de preparar o terreno, nos cuidados com a plantação e nos rituais de colheita, em que se envolviam homens, mulheres e crianças de seu vilarejo, criando diversas imagens de resistência ao imperialismo belga. Isso não causa estranhamento no leitor diante da constatação da autora de que o sorgo era um "ruandês legítimo", "exercia sua resistência" na origem e na permanência em solo ocupado. Nas práticas de eliminação de pragas e preparo do terreno, dava-se um trabalho lento e minucioso, mas que permitia aos ruandeses conversar e contar histórias, algumas das quais conhecemos por meio de Mukasonga.

No quinto capítulo do livro, a autora também descreve o estado generalizado de doença entre os refugiados no campo de Gitagata. Esses refugiados acometidos pela disenteria contavam apenas com a experiência dos mais antigos, com um veterinário que costumava recomendar plantas medicinais e com as habilidades da mãe de Mukasonga, uma curandeira do tipo da maioria das ruandesas, com sua "farmácia vegetal em torno da casa". Na descrição dos tratamentos, apresenta-se a cisão entre o modo tradicional e o colonial de cuidar de enfermidades.

No entanto, apesar de conhecer diversas plantas medicinais e rituais de cura, ainda faltava às crianças "a fonte da vida", o leite. Para o pesar das mães, sem a possibilidade de criar gado, os tutsis 
de Nyamata tinham suas crianças desprotegidas "das desgraças e das doenças". A violência do desterro que parecia tão forte no primeiro capítulo do livro com a batida dos militares nos lares improvisados do acampamento se perpetua também na impossibilidade dos tutsis continuarem sua cultura alimentar. Afinal, "ainda podemos ter a dignidade de um homem se não temos mais o nosso gado?".

Um dos medicamentos de Nyamata era o pão, utilizado sempre como último recurso para as crianças já moribundas. Esse alimento-remédio também conferia sinal de distinção àqueles que o consumiam e essas pessoas sabiam do valor que lhes era atribuído por poderem comê-lo. Talvez o mais importante desse capítulo dedicado ao pão seja a constatação da autora de que o consumo de pães transformava Nyamata em um lugar "civilizado", sem, contudo, "ameaçar a solidariedade da comunidade de desterrados nem trazer a discórdia para dentro das famílias".

O capítulo A beleza e os casamentos é o único do livro em que Mukasonga começa sua narrativa por um ensinamento cristão e não pelas práticas tradicionais tutsis. Por terem de resguardar os domingos, os tutsis iam à missa pela manhã, enquanto, à tarde, os homens buscavam cerveja de sorgo entre os vizinhos e as mulheres cuidavam da beleza ou conversavam com Stefania sobre as jovens em busca de casamento. Na infância de Mukasonga, o costume tutsi de manter o cabelo preso (ou cortado) em um amasunzu indicava as jovens em idade de se casar. Já na sua adolescência em Butare, esse costume era considerado "arcaico e degradante" e imperava o cabelo alisado, a pente aquecido ou a ferro de carvão vegetal.

As qualidades e os critérios de beleza das jovens em idade de se casar mencionados por Mukasonga revelam um conjunto de valores particular, ora semelhante, ora distinto do nosso olhar ocidental contemporâneo. Para os de sua etnia, importava se a moça era de uma família respeitável, se ela demonstrava uma boa educação, se era trabalhadora, se apresentava sinais de fecundidade, se "ao caminhar, o seu balanço seria, como na canção, tão cheio de graça como o balançado da vaca", se "seus olhos tinham o charme irresistível de uma bezerra", se "suas pernas eram cobertas por 
uma fina rede de estrias", ou ainda se seus rostos tinham uma cabeleira abundante, um nariz reto, gengivas pretas e dentes afastados. Sem espelhos em Gitagata, "o único espelho eram os outros". Olhares satisfeitos ou suspiros de desânimo, comentários das colegas, rumores pelo vilarejo serviam de parâmetro às ruandesas tutsis, de maneira que "nosso rosto nunca era nosso como quando é visto no espelho, ele era sempre de outro".

Assuntos como doenças sexualmente transmissíveis e a prática de estupros por militantes extremistas (como armas estratégicas do genocídio) são abordados por Mukasonga, que expõe, quando possível, as soluções elaboradas pelas mulheres de sua comunidade, como os rituais de purificação. No entanto, ao saltar bruscamente para o ano de 1994, a autora conclui que não havia cerimônia de purificação forte o bastante para barrar a transmissão do vírus HIV e a difusão de rumores de que as mulheres estupradas "eram portadoras da morte", ainda que tenham sido essas mulheres a "fonte viva de coragem e a força" que fez sobreviver Ruanda.

A infância e a juventude de Mukasonga também foram repletas de histórias contadas pela sua mãe. Em torno do fogo aceso do inzu, Mukasonga ouvia as narrativas do "país das histórias", assim como as "histórias que são como as poções preparadas pelos envenenadores, histórias cheias de ódio, de morte". Essas histórias contadas pelos brancos ameaçavam o imaginário tutsi, pois atribuíram às suas divindades, aos seus costumes e às suas narrativas certa monstruosidade. Em nome da religião e da ciência, "os brancos pretendiam saber melhor do que nós quem éramos e de onde vínhamos".

No ultimo capítulo do livro, Mukasonga dá ainda mais ênfase à sociabilidade das mulheres ruandesas, por ser aquela que testemunhou em primeira mão ou que ouviu de sua mãe. Além do plantio do sorgo e do consumo de cerveja, essas mulheres socializavam em meio à prática de fumar cachimbo. Os costumes narrados evidenciam uma forte solidariedade entre as mulheres, como a ajuda mútua nos momentos em que uma delas não tinha o que dar de comer aos filhos, e uma constante vigília dos costumes tradicionais, apesar do exílio compulsório em Gitagata e da violência militar. "Sempre temos alguma coisa para pedir para uma vizinha. 
Sempre uma vizinha vem pedir alguma coisa". A quebra de um desses costumes, como se apressar na comensalidade ou pular etapas na contração do casamento, era sempre percebida, mas somente às vezes recriminada. Alguns assuntos eram de foro exclusivo das mulheres (o ikigo) e, apenas depois do consentimento de todas, uma decisão era tomada.

Em meio a discursos africanistas e a vozes de resistência, Mukasonga oferece descrições do mundo africano ao Ocidente que desafiam estereótipos e denunciam algumas das ideias que embasaram a dominação imperialista europeia, desde o século XIX. No cenário particular da dominação belga em Ruanda, na segunda metade do século XX, a autora descreve ataques surpresas dos militares e extremistas hutus, assim como a violência sub-reptícia de levar a civilização a povos tidos como bárbaros ou primitivos, presente na educação religiosa compulsória e na difusão de uma cosmovisão que julgava como erradas as histórias cotidianas de mulheres como Stefania e Mukasonga. Como bem lembra Said (2011), no contato imperial entre a intrusão ocidental e a resistência nativa, o domínio é feito não somente sobre a terra, mas também sobre a possiblidade de narrar ou não a história de um povo. Dessa forma, o imperialismo se apresenta como um sistema que subordina uma população à ficção criada pela metrópole dominante, mas também estabelece uma dependência da metrópole em relação aos nativos e territórios dominados, tidos como elementos que necessitam da missão civilizadora.

Além das inúmeras descrições detalhadas dos rituais tradicionais tutsis, a autora delineia uma ruptura e coexistência entre os costumes tradicionais, defendidos por sua mãe, e "as novidades trazidas pelos brancos", algumas das quais adotadas por seu pai. Em todo o livro, a autora não o nomeia, mas nos diz que ele era uma liderança da comunidade de exilados, entusiasta dos novos costumes, católico da legião de Maria convertido, presenteado pelos padres com um par de óculos para ler a bíblia, um frasco de água benta e uma caixa de fósforos. Em alguns momentos, portanto, deparamo-nos com a apreensão de Stefania e o entusiasmo do pai de Mukasonga a respeito do caminho seguido pelos ruandeses sob o imperialismo belga. Esses momentos demonstram aquilo 
que Said (2011) já havia advertido sobre a experiência do imperialismo - de que é impossível ignorar "[...] a interdependência de terrenos culturais onde colonizador e colonizado coexistiram e combateram um ao outro por meio de projeções, assim como de geografias, narrativas e histórias rivais [...]" (SAID, 2011, p. 19).

Também como recomenda Said (2011), é importante pensar que essas poderosas narrativas de resistência que perseguem Mukasonga se transformam em uma narrativa de emancipação, na medida em que são também narrativas de integração entre povos. As histórias de um povo que tentaram excluir da face da Terra e que agora luta por um lugar mostram semelhanças entre visões de mundo combatentes a respeito da importância dada à opinião do outro e ao tabu do sexo; pontos de encontro entre o que é considerado belo em uma mulher; e até mesmo ambivalências em torno da palavra "civilizados" - aqueles descritos como causa de infortúnios e forças a se resistir eram os que sabiam ler e escrever, que tinham uma vida mais abastada, que introduziam as maiores novidades nos costumes de Gitagata e eram os mais invejados por tudo isso.

Em suma, o livro é composto por relatos autobiográficos de Mukasonga, a partir de vivências em que as narrativas não eram escritas, mas sim tecidas ao pé do ouvido, nas mais diversas oportunidades. Em um primeiro momento, as histórias protagonizadas por Stefania parecem ser o cumprimento do vaticínio de que seu espírito perseguiria a filha, faltosa em cobrir o corpo materno mutilado. No entanto, no posfácio da obra, essa impressão é corrigida, pois não é o espírito da mãe morta a perseguir a filha; são os espíritos de todas as vítimas do genocídio tutsi a perseguirem a "civilizada" sobrevivente.

\section{REFERÊNCIAS}

CAZES, L. Inédita no Brasil, Scholastique Mukasonga estará na Flip. O Globo, Rio de Janeiro, 15 abr. 2017. Cultura. Disponível em: <https:// oglobo.globo.com/cultura/livros/inedita-no-brasil-scholastiquemukasonga-estara-na-flip-21212043>. Acesso em: 15 dez. 2018. 
CONSTANT, L. Quem é Scholastique Mukasonga, a escritora africana que vai à Flip?.Radio France Internacional, [online], 21 jul. 2017. Cultura. Disponível em: <http://br.rfi.fr/cultura/20170721-quem-e-scholastiquemukasonga-escritora-africana-que-vai-flip>. Acesso em 15 dez. 2018.

DOMINGOS, M. Resenha de A mulher de pés descalços. Achados e Lidos, [online], 27 jul. 2017. Disponível em: <http://www.achadoselidos.com. $\mathrm{br} / 2017 / 07 / 26 /$ resenha-a-mulher-de-pes-descalcos/>. Acesso em: 15 dez. 2018.

GABRIEL, R. de S. Scholastique Mukasonga: "me tornei a guardiã da memória do meu povo". Época, Rio de Janeiro, 28 jul. 2017. Cultura. Disponível em: <https://epoca.globo.com/cultura/noticia/2017/07/ scholastique-mukasonga-me-tornei-guardia-da-memoria-do-meu-povo. html>. Acesso em: 15 dez. 2018.

KUBOTA, M. Scholastique Mukasonga reverencia as ruandesas em "A mulher de pés descalços". Escotilha, [online], 08 mai. 2018. Ponto e Vírgula. Disponível em: <http://www.aescotilha.com.br/literatura/pontovirgula/scholastique-mukasonga-a-mulher-de-pes-descalcos-editoranos-resenha/>. Acesso em: $15 \mathrm{dez} .2018$.

MELLO, P. C. "Escrevo para salvaguardar memória", diz ruandesa Scholastique Mukasonga. Folha de S. Paulo, São Paulo, 26 jul. 2018. Ilustrada. Disponível em: <https://www1.folha.uol.com.br/ ilustrada/2017/07/1904391-escrevo-para-salvaguardar-memoria-dizruandesa-scholastique-mukasonga.shtml>. Acesso em: 15 dez. 2018.

NETO, R. Resenha de "A mulher de pés descalços", de Scholastique Mukasonga. SP Review, [online], 20 jul. 2017. Disponível em: <http:// saopauloreview.com.br/resenha-a-mulher-de-pe-descalcos-descholastique-mukasonga/>. Acesso em: 15 dez. 2018.

NEVES, M. L. Scholastique Mukasonga lança dois livros durante a Flip. Marie Claire, [online], 21 jul. 2017. Notícias. Disponível em: <https:// revistamarieclaire.globo.com/Noticias/noticia/2017/07/scholastiquemukasonga-lanca-dois-livros-durante-flip.html>. Acesso em: 15 dez. 2018.

RODRIGUES, M. F. Scholastique Mukasonga não quis escrever livros sobre o horror, mas ele está em todo lugar. Estadão, São Paulo, 30 jun. 2018. Cultura. Disponível em: <https://cultura.estadao.com.br/noticias/ literatura,scholastique-mukasonga-nao-quis-escrever-livros-sobre-ohorror-mas-ele-esta-em-todo-lugar,70002377321>. Acesso em: $15 \mathrm{dez}$. 2018.

SAID, E. Cultura e imperialismo. São Paulo: Companhia de Bolso, 2011. 
SANTOS, E. Do amor materno e das dores: A mulher de pés descalços. Homo Literatus, [online], 10 ago. 2017. Disponível em: <https:// homoliteratus.com/a-mulher-de-pes-descalcos/>. Acesso em: $15 \mathrm{dez}$. 2018.

SOBOTA, G. Genocídio em Ruanda transformou Scholastique Mukasonga em escritora. Estadão, São Paulo, 27 jul. 2017. Cultura. Disponível em: <https://cultura.estadao.com.br/noticias/ literatura, genocidio-em-ruanda-transformou-scholastique-mukasongaem-escritora,70001909351>. Acesso em: 15 dez. 2018.

TORRES, B.; CAZES, L. Flip 2017: Noemi Jaffe e Sholastique Mukasonga criticam "cegueira" diante de genocídios. O Globo, Rio de Janeiro, 28 jul. 2017. Cultura. Disponível em: <https://oglobo.globo.com/cultura/livros/ flip-2017-noemi-jaffe-scholastique-mukasonga-criticam-cegueira-diantede-genocidios-21640591 >. Acesso em: 15 dez. 2018. 